\title{
A Novel Mechanism for the Generation of Superoxide Anions in Hematoporphyrin Derivative-mediated Cutaneous Photosensitization
}

\author{
Activation of the Xanthine Oxidase Pathway
}

\author{
Mohammad Athar, Craig A. Elmets, David R. Bickers, and Hasan Mukhtar \\ Department of Dermatology, Case Western Reserve University, University Hospitals of Cleveland; \\ and Veterans Administration Medical Center, Cleveland, Ohio 44106
}

\begin{abstract}
Prior studies, both in vitro and in vivo, have suggested that cutaneous porphyrin photosensitization requires the generation of superoxide anion $\left({ }^{\circ} \mathrm{O}_{2}^{-}\right)$and various other reactive oxygen metabolites. No unifying concept has emerged, however, that unequivocally demonstrates the source of generation of these species. Since xanthine oxidase is known to generate ${ }^{\circ} \mathrm{O}_{2}^{-}$ in reperfused ischemic tissue and in certain inflammatory disorders, we attempted to assess its role in porphyrin photosensitization. C3H mice were rendered photosensitive by the intraperitoneal administration of dihematoporphyrin ether (DHE) $(5 \mathrm{mg} / \mathrm{kg})$ followed by irradiation with visible light. Murine ear swelling was used as a marker of the acute photosensitization response and involvement of oxygen radicals was evaluated using electron spin resonance (ESR) spectroscopy. The administration of allopurinol, a potent inhibitor of xanthine oxidase, afforded $90 \%$ protection against DHE-mediated acute photosensitivity in vivo. Furthermore, xanthine oxidase activity was twofold higher in the skin of photosensitized mice than in unirradiated animals. ESR spectra of 5,5-dimethyl-1pyrroline $\boldsymbol{N}$-oxide-trapped radicals from the skin of photosensitized mice verified the presence of ${ }^{\circ} \mathrm{O}_{2}^{-}$and ${ }^{\circ} \mathrm{OH}$, while neither of these species was detected in the skin of control mice or mice receiving allopurinol. The administration of a soybean trypsin inhibitor or verapamil before irradiation also partially blocked the photosensitivity response, suggesting that calcium-dependent proteases play a role in the activation of xanthine oxidase in this photodynamic process. These data provide in vivo evidence for the involvement of ${ }^{\circ} \mathrm{O}_{2}^{-}$in DHE-mediated cutaneous photosensitization and suggest that these radicals are generated through the activation of the xanthine oxidase pathway. The administration of allopurinol and calcium channel blockers may thus offer new approaches for the treatment of cutaneous porphyrin photosensitization.
\end{abstract}

\section{Introduction}

Skin photosensitization is a major manifestation of some forms of human porphyria and is also a major drawback that

Dr. Athar is on leave from the Industrial Toxicology Research Centre, Lucknow, India.

Address correspondence to Dr. Hasan Mukhtar, Veterans Administration Medical Center, 10701 East Boulevard, Cleveland, $\mathrm{OH}$ 44106.

Received for publication 23 June 1988 and in revised form 14 October 1988.

J. Clin. Invest.

(c) The American Society for Clinical Investigation, Inc.

0021-9738/89/04/1137/07 \$2.00

Volume 83, April 1989, 1137-1143 limits the widespread use of porphyrins in the photodynamic therapy (PDT), ${ }^{1}$ a unique modality for the diagnosis and management of various malignant neoplasms $(1,2)$. The porphyrins most widely used for PDT are hematoporphyrin derivative (HPD), also known as Photofrin-I, and its active tumorlocalizing component, dihematoporphyrin ether (DHE), also known as Photofrin-II $(3,4)$, both of which are complex mixtures of porphyrins and their aggregated ether or ester products. Both DHE and HPD mediate their phototoxic effects through oxygen-mediated membrane damage $(5,6)$. Prior in vitro studies have demonstrated the production of both singlet oxygen $\left({ }^{1} \mathrm{O}_{2}\right)$ and superoxide anion $\left({ }^{\circ} \mathrm{O}_{2}^{-}\right)$in this process $(7,8)$. These radical anions, free radicals, and other oxidants derived from them have also been implicated in the pathogenesis of various inflammatory diseases, ischemic reperfusion injury, and tumor promotion, and in the toxicity of various chemicals such as paraquat $(9-11)$.

$\mathrm{O}_{2}^{-}$may also play an important role in the development of acute cutaneous photosensitivity in vivo. We have recently demonstrated that the in vivo acute cutaneous photosensitivity response in mice can be inhibited by pretreating animals with bis $(3,5$ diisopropyl salicylato $)(0,0)$ copper(II), a SOD mimic. Moreover, we have also found that the photosensitivity response can be augmented by sodium diethyldithiocarbamate, a SOD inhibitor (12).

The source of generation of reactive oxygen species in cutaneous porphyrin photosensitization in vivo has widely been regarded to be solely the direct photosensitizer-mediated transfer of energy to oxygen $(1,5,6)$. However, enzyme-catalyzed pathways for the reduction of oxygen are a potential alternate source of reactive oxygen intermediates. Using DHE as a model porphyrin, the purpose of the current study was to determine the mechanism by which oxygen intermediates are generated in acute cutaneous porphyrin photosensitization. Our data indicate that ${ }^{\circ} \mathrm{O}_{2}^{-}$are generated in this process through a calcium-dependent, protease-mediated activation of xanthine oxidase in skin, and thus identify a new mechanism for the generation of reactive oxygen species in hematoporphyrin-mediated photosensitization.

\section{Methods}

Chemicals. Soybean trypsin inhibitor (STI), verapamil, allopurinol, 5,5 dimethyl-1-pyrroline $N$-oxide (DMPO), catalase, SOD, aldehyde dehydrogenase, xanthine, and hypoxanthine were obtained from Sigma Chemical Co., St. Louis, MO. DHE was a generous gift from

1. Abbreviations used in this paper: DHE, dihematoporphyrin ether; DMPO, 5,5 dimethyl-1-pyrroline $N$-oxide; ESR, electron spin resonance; HPD, hematoporphyrin derivative; ${ }^{\circ} \mathrm{O}_{2}^{-}$, superoxide anion; ${ }^{1} \mathrm{O}_{2}$, singlet oxygen; PDT, photodynamic therapy; STI, soybean trypsin inhibitor. 
Photofrin Inc., Raritan, NJ. All other chemicals were purchased in the highest purity commercially available.

Animals. Female C3H mice (6-8 wk old) obtained from the Charles River Breeding Laboratories Inc., Wilmington, MA, were used in this study.

Administration of photosensitizers, quenchers, and inhibitors. DHE solution, prepared in the dark at a concentration of $1 \mathrm{mg} / \mathrm{ml}$ in normal saline (pH 7.4), was injected intraperitoneally to mice at a dose of 5 $\mathrm{mg} / \mathrm{kg}$ body wt (13). After injection with the photosensitizer the mice were kept in light-protected housing except while undergoing irradiation. For studies of the effect of quenchers and inhibitors the animals received subcutaneously either allopurinol, STI, or verapamil at the desired dosage $2 \mathrm{~h}$ before irradiation. Animals receiving vehicle alone served as control. In each experiment at least four mice were used in each group. The dosage regimens were selected based on previous studies (14-16).

Irradiation procedure. Mice were irradiated for $2.5 \mathrm{~h}$ in individual cubicles of a Plexiglas cage at a light to target distance of $23 \mathrm{~cm}$. The light source was a $5 \mathrm{~kW}$ metal halide lamp doped with zinc and cadmium oxides. Emission peaks were present in the range of 480 to 645 $\mathrm{nm}$ and there was no appreciable emission below $450 \mathrm{~nm}$. Mice were irradiated beginning $6 \mathrm{~h}$ after injection of DHE, since preliminary studies indicate that maximum uptake of the drug in the skin occurs at this time interval (17).

Quantitation of cutaneous photosensitivity. Cutaneous photosensitization was determined by measuring the degree of ear swelling that developed after irradiation compared with that before irradiation. Each ear was measured three times using a dial thickness gauge micrometer (Mitutoya Co., Tokyo, Japan) within $1 \mathrm{~h}$ of irradiation as described previously $(18,19)$. These values were compared with the measured ear thickness before irradiation and the increment in ear thickness was determined by subtracting the ear thickness before irradiation from the ear thickness after irradiation.

Histopathology. Immediately after the measurement of ear swelling the mice were killed and their ears were excised and fixed in $10 \%$ buffered formalin. Hematoxylin and eosin preparations of processed sections were prepared for microscopic examination. Mast cell staining (Leder stain) was also carried out in selected animals.

Electron spin resonance (ESR) spectral measurements. The ESR spectra of DMPO-trapped radicals in skin homogenates were recorded on an X-band ESR spectrometer (model 112; Varian Associates, Inc., Palo Alto, CA) having cavity model TM110 in an aqueous quartz flat cell at room temperature. Homogenates from the dorsal skin of animals were prepared in $10 \mathrm{vol}$ of $0.1 \mathrm{M}$ phosphate buffer, $\mathrm{pH} 7.4$, as described earlier (20). The reaction mixture in a total vol of $0.5 \mathrm{ml}$ contained $0.3 \mathrm{ml}$ homogenate, $0.2 \mathrm{M}$ DMPO in phosphate buffer $(0.1$ $\mathrm{M}), \mathrm{pH}$ 7.4, and desired concentration of SOD/catalase as described in Fig. 3. The spectrometer conditions were: gain, $6.3 \times 10^{4}$; modulation amplitude, $5 \mathrm{G}$; microwave power, $20 \mathrm{~mW}$; scan time, 4 min; modulation frequency, $100 \mathrm{kHz}$; field set, 3,360 G; scan range, $100 \mathrm{G}$; time constant, $0.25 \mathrm{~s}$; and microwave frequency, $9.425 \mathrm{GHz}$.

Estimation of xanthine oxidase. Xanthine oxidase activity was measured by the method of Heinz and Reckel (21) in 10,000-g supernatant fractions of $10 \%$ skin homogenate. Briefly, the total reaction mixture $(1.5 \mathrm{ml})$ in phosphate buffer $(0.1 \mathrm{M}), \mathrm{pH} 7.4$, containing 1 mM EDTA, $130 \mathrm{U}$ catalase, $0.1 \mathrm{ml}$ absolute ethanol, $500 \mu \mathrm{g} \mathrm{NADP}{ }^{+}$, $2.5 \mathrm{U}$ aldehyde dehydrogenase, $0.09 \mu \mathrm{mol}$ xanthine, and $0.5 \mathrm{ml}$ enzyme preparation. The change in OD was recorded for $5 \mathrm{~min}$ at 340 $\mathrm{nm}$. The specific activity was calculated as described by Heinz and Reckel (21).

Estimation of xanthine and hypoxanthine on HPLC. Skin tissue samples $(1 \mathrm{~g})$ were homogenized in $6 \mathrm{ml}$ perchloric acid $(60 \mathrm{ml} /$ liter $)$ and centrifuged for $30 \mathrm{~min}$ at $3,500 \mathrm{~g}$. The supernatant was added to an equal volume of tri- $n$-octylamine in freon $(600 \mathrm{ml} /$ liter $)$ to remove perchlorate. After vortexing for $2 \mathrm{~min}$, the solution was centrifuged and the upper layer was removed, concentrated, and redissolved in $\mathbf{0 . 2}$ $\mathrm{ml}$ of 0.1-M phosphate buffer, $\mathrm{pH}$ 7.4. Standard solutions were prepared at a concentration of $1 \mathrm{nmol} / \mathrm{liter}$ in $\mathrm{KH}_{2} \mathrm{PO}_{4}, \mathrm{pH} 4.8$, and xanthine and hypoxanthine were separated and estimated by HPLC exactly as described by McBurney and Gibson (22).

\section{Results}

Effect of pretreatment with allopurinol on DHE-mediated cutaneous photosensitization. In a recent report we have demonstrated that treatment of animals with SOD mimic (a quencher of ${ }^{\circ} \mathrm{O}_{2}^{-}$) before irradiation substantially reduced DHE-mediated skin photosensitization while $\beta$-carotene (a quencher of ${ }^{1} \mathrm{O}_{2}$ ) and DMSO (a scavenger of ${ }^{\circ} \mathrm{OH}$ ) were only moderately effective in this regard (12). Furthermore, sodium diethyldithiocarbamate (an inhibitor of SOD) and hydroxylamine and 4aminotriazole (inhibitors of catalase) significantly potentiated the skin photosensitization response. Based on these observations we suggested that ${ }^{\circ} \mathrm{O}_{2}^{-}$is involved in DHE-mediated skin photosensitization (12). In this study we further evaluated the involvement and source of generation of ${ }^{\circ} \mathrm{O}_{2}^{-}$in cutaneous porphyrin photosensitization. ${ }^{\circ} \mathrm{O}_{2}^{-}$may be generated by the transfer of an electron from an excited photosensitizer to oxygen (type I reaction). Other biochemical pathways such as that mediated by xanthine oxidase are potential alternate routes (23). We, therefore, evaluated the role of xanthine oxidase in the generation of ${ }^{\circ} \mathrm{O}_{2}^{-}$during DHE-mediated skin photosensitization. This enzyme is thought to be responsible for the $\mathrm{O}_{2}^{-}$mediated tissue injury occurring in ischemia followed by reperfusion and in various other diseases (24). To assess the role of this enzyme in the generation of ${ }^{\circ} \mathrm{O}_{2}^{-}$we pretreated mice with allopurinol, a potent inhibitor of xanthine oxidase activity (25). Our prior studies established that the murine ear swelling response is a reliable index of cutaneous porphyrin photosensitization (19), and that the administration of DHE followed by irradiation with visible light resulted in a $217 \%$ increase in ear swelling, while irradiated or nonirradiated mice receiving vehicle alone showed no such response (12). The data in Fig. 1 show that allopurinol had a dose-dependent inhibitory effect on cutaneous photosensitization and afforded nearly $90 \%$ protection at a dose level of $1 \mathrm{mM} / \mathrm{kg}$ body wt. Histologic sections from ears of mice treated with DHE with and without pretreatment of allopurinol were examined for the degree of edema, vascular ectasia, neutrophilic infiltrate, mast cell infiltrate, and mast cell degranulation. Comparison of sections from DHE-treated mice with untreated controls revealed that DHE caused considerable edema with marked increases in vascular ectasia, neutrophilic infiltrate, mast cell infiltrate, and mast cell degranulation. Most of these changes were significantly alleviated in mice pretreated with allopurinol (Fig. 2).

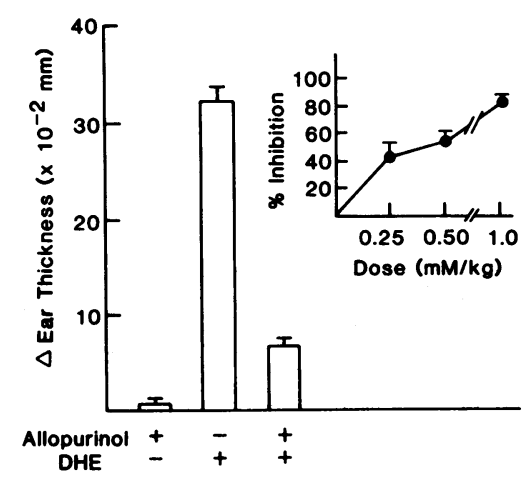

Figure 1. Effect of allopurinol on DHE-mediated ear swelling response in $\mathrm{C} 3 \mathrm{H}$ mice. Allopurinol ( $1 \mathrm{mM} / \mathrm{kg})$ was administered $2 \mathrm{~h}$ before irradiation. Inset shows the dose-response relationship. For other details see text. 

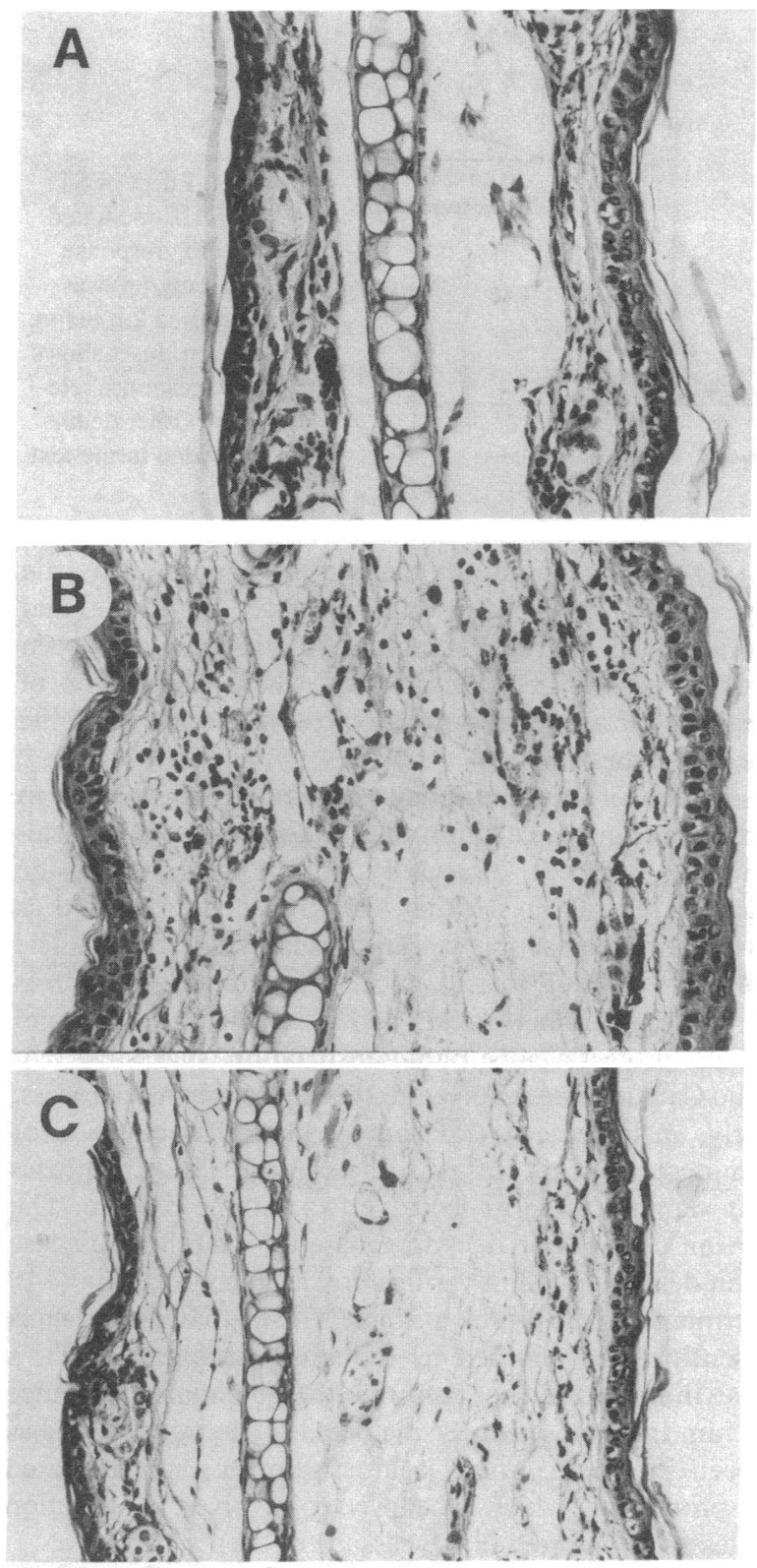

Figure 2. Histopathological sections of ears of $(A)$ normal untreated, $(B)$ DHE-treated, and $(C)$ DHE- and allopurinol-treated animals. Specimens were taken within $1 \mathrm{~h}$ of irradiation and stained with hematoxylin and eosin $(\times 300)$. Other details are provided in the text.

ESR spectra of DMPO-trapped, oxygen-centered radicals from control, DHE-photosensitized, and allopurinol-treated, DHE-photosensitized skin. To support our hypothesis that ${ }^{\circ} \mathrm{O}_{2}^{-}$ is produced through the activation of xanthine oxidase and that ${ }^{\circ} \mathrm{OH}$ are produced from ${ }^{\circ} \mathrm{O}_{2}^{-}$via the Haber-Weiss and Fenton reactions, we used ESR spin trapping techniques to directly measure and characterize the oxygen radicals. DMPO is an extremely efficient spin trap for oxygen-centered radicals (26). It was used in the present study to probe the generation of $\mathrm{O}_{2}^{-}$and ${ }^{\circ} \mathrm{OH}$ in DHE-mediated cutaneous photosensitization and also to clarify the role of xanthine oxidase in this process. As shown in Fig. 3, no signal could be detected for any of these radicals in control nonphotosensitized skin (spectrum $A$ ), whereas the spectrum from DHE-treated skin (spectrum $B$ ) showed a number of signals consisting of two major components. One component with the coupling constants $A_{\mathrm{N}}=14.4$ $\mathrm{G}$ and $A_{\mathrm{H}}=11.4 \mathrm{G}$ was suggestive of DMPO-trapped ${ }^{\circ} \mathrm{O}_{2}^{-}$and the other component, a quartet (1:2:2:1) with the coupling constants $A_{\mathrm{N}}=A_{\mathrm{H}}=14.9 \mathrm{G}$ was suggestive of DMPO-trapped $\circ \mathrm{OH}(27-29)$. The spectra were further resolved in the presence of SOD and catalase. The signals due to ${ }^{\circ} \mathrm{O}_{2}^{-}$disappeared in the presence of SOD (spectrum $C$ ), while the signals due to ${ }^{\circ} \mathrm{OH}$ showed a diminishing trend in the presence of increasing concentrations of catalase (spectra $D$ and $E$ ). However, no signal could be observed in spectra obtained from allopurinol-pretreated, DHE-photosensitized skin (spectrum $F$ ).

Effect of DHE-mediated skin photosensitization on cutaneous xanthine oxidase activity. We next attempted to determine whether DHE-mediated skin photosensitization was associated with increased xanthine oxidase activity. As shown in Fig. 4, the activity of this enzyme increased more than twofold in DHE-photosensitized skin, and in allopurinol-pretreated animals there was significant inhibition in this response.

Effect of STI and verapamil on DHE-mediated cutaneous photosensitization. Xanthine oxidase is normally present in tissues as xanthine dehydrogenase (30). However, xanthine dehydrogenase is readily converted to xanthine oxidase in the presence of a calcium-dependent protease $(31,32)$. Since photosensitizers are known to disrupt mitochondrial membranes, it is possible that an influx of $\mathrm{Ca}^{2+}$ into the cytoplasm may activate the $\mathrm{Ca}^{2+}$-dependent protease, resulting in the activation of xanthine oxidase (31). We, therefore, studied the effect of a protease inhibitor, STI (Fig. 5), and a calcium channel blocker, verapamil (Fig. 6), on DHE-mediated cutaneous photosensitization. Both of these agents diminished the DHE-mediated cutaneous photosensitization in a dose-dependent manner.

\section{Discussion}

The phototoxic action of a photosensitizer requires its localization in tissues where it can absorb incident radiant energy. The hydrophobic components of HPD include DHE, which is known to localize within the membranous structures including those of the plasma membrane and subcellular organelles like mitochondria, the endoplasmic reticulum, and lysosomes (20, 33-37). Membranes, therefore, appear to be the principal targets for the phototoxic action of porphyrins. Porphyrins absorb light in the visible spectrum and the excited photosensitizer transfers its absorbed energy to an oxygen molecule through a type I or type II reaction $(36,38,39)$.

The oxidative species that are produced through type I and/or type II reactions cause damage to various proteins within plasma membranes or subcellular organelles $(20,34$, 35). In PDT this damage may not be sufficient in itself to ablate an entire tumor mass or to result in protracted cutaneous photosensitization. However, damage to mitochondrial membranes may be a crucial step in this process for it may lead to a cascade of reactions that culminates in substantial tissue damage (40). As observed in photosensitized tissues, damage to mitochondrial membrane proteins such as cytochrome $c$ oxidase, $\mathrm{Ca}^{2+}$ ATPase, etc., and the uncoupling of oxidative phosphorylation and cellular respiration result in the degradation of high-energy phosphate compounds manifested by a decrease in ATP level and a concomitant increase in the level 


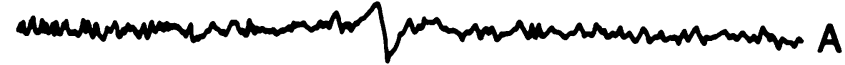
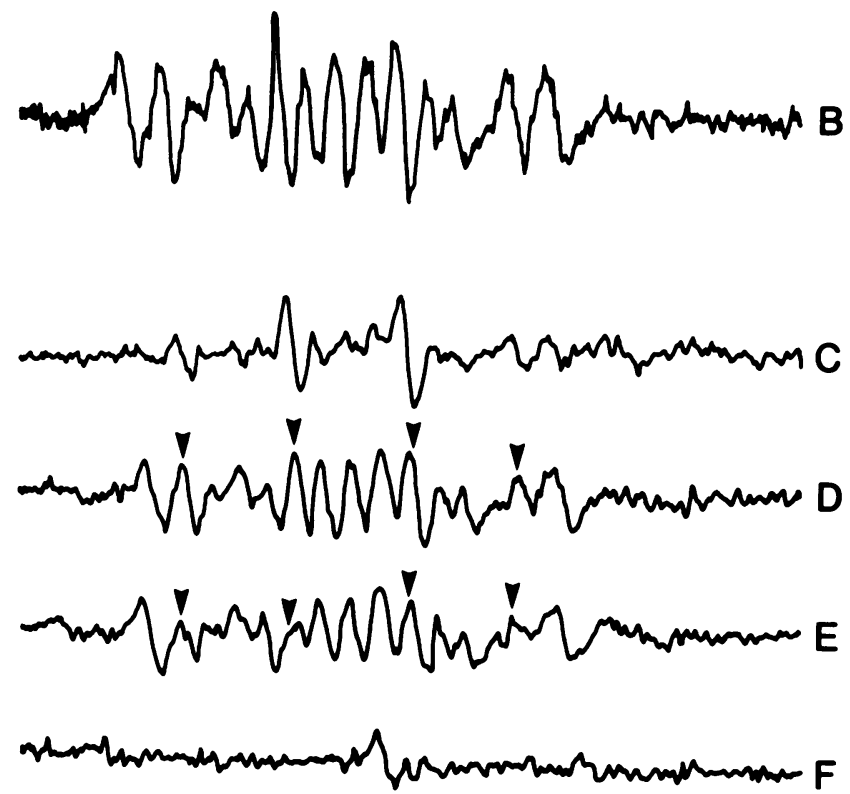

Figure 3. ESR spectra of DMPO-trapped, oxygen-centered radicals from control, DHE-photosensitized, and allopurinol-treated, DHEphotosensitized mouse skin. The spectra were recorded in an aqueous quartz flat cell. The reaction mixture contained $10 \%$ skin homogenate in $0.1 \mathrm{M}$ phosphate buffer, $\mathrm{pH} 7.4$, containing $0.2 \mathrm{M}$ DMPO. (A) Skin homogenate from control mice. (B) Skin homogenate from DHE-photosensitized mice showing the generation of ${ }^{\circ} \mathrm{O}_{2}^{-}$ and $\mathrm{OH}$. (C) Skin homogenate from DHE-photosensitized mice containing $2,000 \mathrm{U} / \mathrm{ml}$ of SOD. Note the disappearance of ESR signals due to DMPO-trapped ${ }^{\circ} \mathrm{O}_{2}^{-}\left(A_{\mathrm{N}}=14.4 \mathrm{G}\right.$ and $\left.A_{\mathrm{H}}=11.4 \mathrm{G}\right)$. ( $D$ and $E$ ) Skin homogenate from DHE-photosensitized mice containing 250 and $500 \mathrm{U} / \mathrm{ml}$ of catalase, respectively. Note continuous disappearance of signals due to DMPO-trapped ${ }^{\circ} \mathrm{OH}\left(A_{\mathrm{N}}=14.9 \mathrm{G}\right.$ and $\left.A_{\mathrm{H}}=14.9 \mathrm{G}\right)$ as indicated by arrows. $(F)$ Skin homogenate from allopurinol-treated, DHE-photosensitized mice showing complete disappearance of radical signals. Spectrometer conditions: gain, 6.3

$\times 10^{4}$; modulation amplitude, $5 \mathrm{G}$; microwave power, $20 \mathrm{~mW}$; scan time, $4 \mathrm{~min}$; modulation frequency, $100 \mathrm{~Hz}$; field set, 3,360 G; scan range, $100 \mathrm{G}$; time constant, $0.25 \mathrm{~s}$; microwave frequency, 9.425 GHz. X-band 112 cavity TM1 10 (Varian Associates, Inc.). For other details see text.

of inorganic phosphate $(41,42)$. This may also be visualized in $P^{31}$ NMR spectra of the photosensitized tissues which show a gradual time-dependent disappearance of the ATP phosphoric acid ester signal with a concomitant increase in the intensity of the inorganic phosphate signal (43). It is also corroborated by the present observation of increased levels of hypoxanthine and xanthine in the skin of photosensitized mice (data not

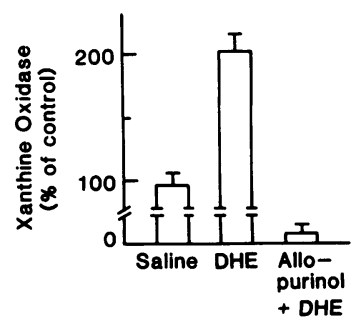

Figure 4. Xanthine oxidase activity in control, DHE-photosensitized, and allopurinol-treated, DHE-photosensitized mouse skin. Data are expressed as percent of control.

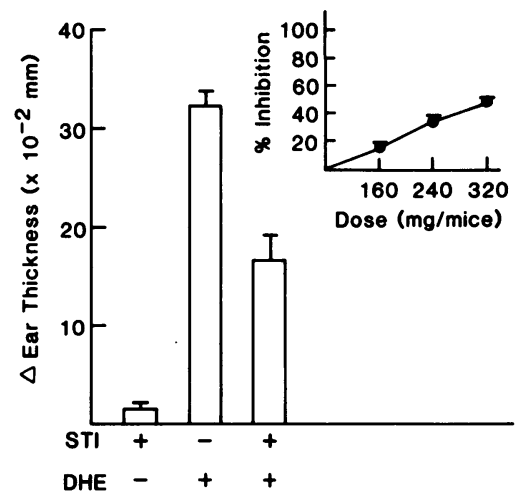

Figure 5. Effect of STI on the DHE-mediated ear swelling response. STI $(320 \mathrm{mg} / \mathrm{kg})$ was administered $2 \mathrm{~h}$ before irradiation. Inset shows the dose-response relationship. Other details are provided in the text.

shown). Hypoxanthine and xanthine are generated by the stepwise catabolism of ATP to ADP, AMP, adenosine, and inosine as shown in Fig. 7. Such a situation has also been observed in various ischemic diseases, where degradation of ATP leads to the accumulation of hypoxanthine and xanthine in ischemic tissues (31).

Disruption of mitochondrial calcium ATPase results in impaired pumping of calcium, thus causing an influx of calcium into the cytosol. Increased cytosolic calcium may be damaging in several ways. It may lead to vasocontriction, thus decreasing the blood supply within photosensitized tissue. The pretreatment of DHE-treated mice with verapamil, which is both a calcium channel blocker and a vasodilator, was found to partially protect against photosensitization, suggesting that cytosolic $\mathrm{Ca}^{2+}$ may be involved in this photodynamic process. Similarly, an increase in $\mathrm{Ca}^{2+}$ may lead to the activation of calcium-dependent proteases in the cytosol. These proteases convert xanthine dehydrogenase into xanthine oxidase. The conversion of xanthine dehydrogenase into xanthine oxidase has been demonstrated in various organs, including skin (44). Furthermore, the protection against DHE-mediated cutaneous photosensitization afforded by the administration of STI, a protease inhibitor, further confirms the potential importance of calcium in photosensitizer-mediated tissue injury. STI has also been shown to protect against phorbol ester-mediated tumor promotion, which is believed to involve the activation of proteases as one step in the cascade of events (45).

Xanthine dehydrogenase and xanthine oxidase are enzymes of the purine catabolic pathway. Xanthine dehydrogenase catalyzes the conversion of hypoxanthine into xanthine $(24,31)$ using $\mathrm{NAD}^{+}$(hypoxanthine $+\mathrm{NAD}^{+}+\mathrm{H}_{2} \mathrm{O} \rightarrow$ xanthine $+\mathrm{NADH}+\mathrm{H}^{+}$). However, once this enzyme is

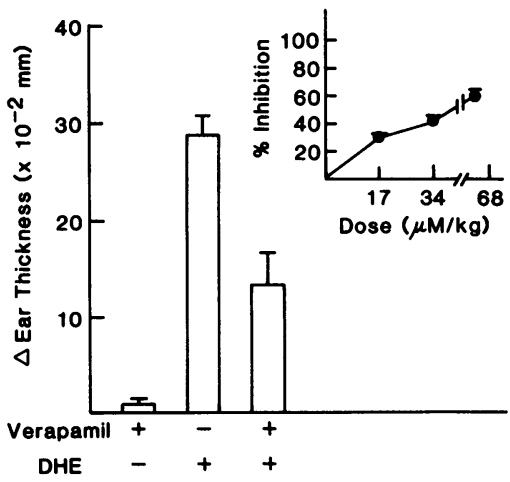

Figure 6. Effect of verapamil on the DHE-mediated ear swelling response. Verapamil $(68$ $\mu \mathrm{M} / \mathrm{kg}$ ) was administered $2 \mathrm{~h}$ before irradiation. Inset shows the dose-response relationship. Other details are provided in the text. 


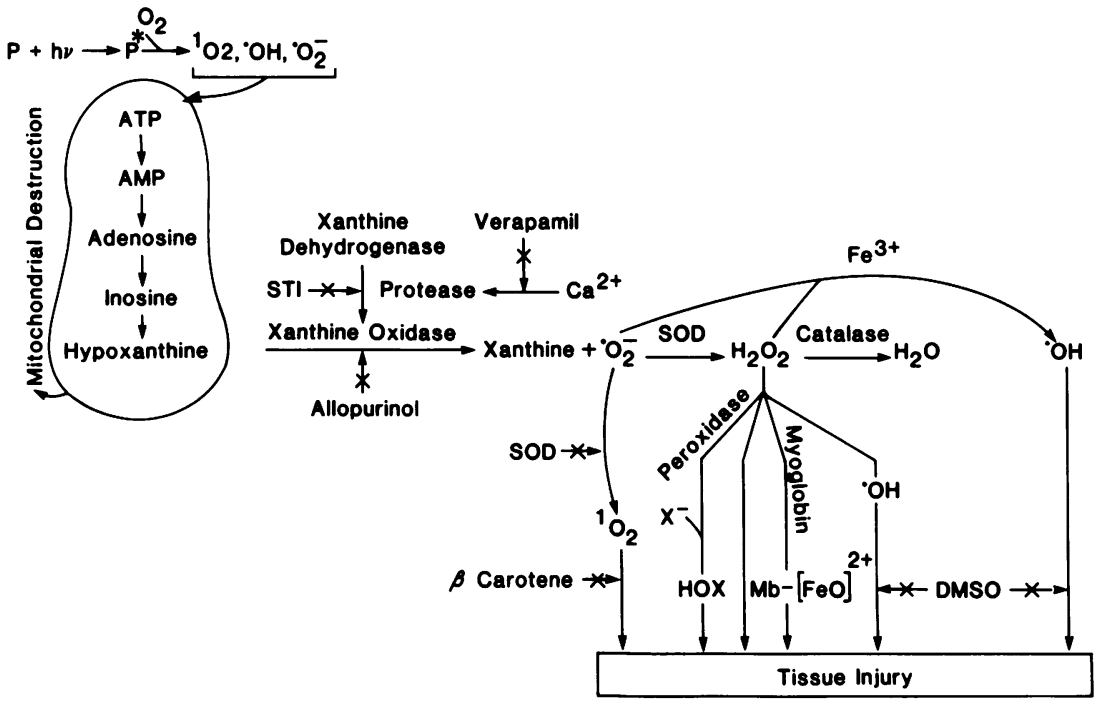

Figure 7. Proposed mechanism for porphyrin photosensitization in skin. Photosensitizer $(P)$ localizes in cellular membranes. On exposure to light, the photosensitizer absorbs energy and is raised to an excited state $\left(P^{*}\right)$ which can transfer its energy to oxygen, thereby generating various reactive oxygen metabolites that damage mitochondrial membranes resulting in the catabolism of high-energy phosphates leading to increased formation of hypoxanthine/xanthine. In addition, it also leads to impaired pumping of calcium. The increase in cytosolic calcium may activate calcium-dependent protease which converts xanthine dehydrogenase into xanthine oxidase. Xanthine oxidase uses hypoxanthine/xanthine as substrates along with $\mathrm{O}_{2}$ and produces an efflux of ${ }^{\circ} \mathrm{O}_{2}^{-}$. These anions are converted to various other strong oxidants that exacerbate tissue injury. The compounds indicated by an arrow with a cross are quenchers or inhibitors that afford protection against the damage of the respective species. transformed to xanthine oxidase, which in normal tissues is present in low concentrations (30), oxygen is used (24) and $\mathrm{O}_{2}^{-}$ is produced (hypoxanthine $+2 \mathrm{O}_{2}+\mathrm{H}_{2} \mathrm{O} \rightarrow$ xanthine $+2^{\circ} \mathrm{O}_{2}^{-}$). As described here, xanthine oxidase activity was elevated in DHE-photosensitized tissue, and cutaneous photosensitization was reduced by $90 \%$ in mice pretreated with allopurinol, an inhibitor of this enzyme. In addition, our previous study showed that porphyrin-mediated skin photosensitization was inhibited by SOD mimic, a scavenger of ${ }^{\circ} \mathrm{O}_{2}^{-}$, and was augmented by inhibitors of SOD and catalase (12), suggesting that in photosensitized tissue xanthine dehydrogenase is converted to xanthine oxidase and elaborates ${ }^{\circ} \mathrm{O}_{2}^{-}$, which, in turn, results in tissue damage. This conclusion is also strengthened by our data showing that ${ }^{\circ} \mathrm{O}_{2}^{-}$and ${ }^{\circ} \mathrm{OH}$ were present in the skin of DHE-photosensitized mice as revealed by ESR spectral measurement of DMPO adducts of these radicals. The DMPO- $\mathrm{O}_{2}^{-}$ adduct is known to be decomposed forming DMPO-OH adduct $(27,46)$. Thus, the presence of a DMPO-OH signal does not necessarily imply the generation of ${ }^{\circ} \mathrm{OH}$ in the system. However, in the present study, since a gradual disappearance of the DMPO-OH signal was observed by adding increasing concentrations of catalase, we suggest that these radicals are also produced during skin photosensitization from hydrogen peroxide, another dismutation product of ${ }^{\circ} \mathrm{O}_{2}^{-}$(47). Further, the absence of any signal in the ESR spectrum of skin from allopurinol-treated animals suggests that the production of these radicals is mediated through the xanthine oxidase pathway.

Our data suggest that ${ }^{\circ} \mathrm{O}_{2}^{-}$is derived from xanthine oxidase activation and that this pathway plays an important role in evoking tissue injury during photosensitization. The chemical reactivity of ${ }^{\circ} \mathrm{O}_{2}^{-}$is modest in comparison with that of other reactive oxygen metabolites derived from it (48). ${ }^{\circ} \mathrm{O}_{2}^{-}$has a very short half-life with a rate constant for dismutation of $2 \times 10^{5}$ $\mathrm{M} / \mathrm{s}$ at $\mathrm{pH} 7.4$ (48). These anions are dismutated both enzymatically and nonenzymatically $(23,29)$ into $\mathrm{H}_{2} \mathrm{O}_{2}$ and $\mathrm{O}_{2}$ $\left(2^{\circ} \mathrm{O}_{2}^{-}+2 \mathrm{H}^{+} \rightarrow \mathrm{H}_{2} \mathrm{O}_{2}+\mathrm{O}_{2}\right) \cdot{ }^{\circ} \mathrm{O}_{2}^{-}$and hydrogen peroxide can interact in the presence of certain transition metal ions, metal chelates, or heme proteins through the Haber-Weiss and Fenton reactions to yield ${ }^{\circ} \mathrm{OH}(49,50)$ as shown below:

$$
\begin{aligned}
& \mathrm{O}_{2}^{-}+\mathrm{Fe}^{+3} \rightarrow \mathrm{O}_{2}+\mathrm{Fe}^{+2} \\
& \mathrm{H}_{2} \mathrm{O}_{2}+\mathrm{Fe}^{+2} \rightarrow{ }^{\circ} \mathrm{OH}+\mathrm{OH}^{-}+\mathrm{Fe}^{+3}
\end{aligned}
$$

Previous studies from our laboratory have shown that the degradation of heme containing proteins, such as cytochrome P-450 and cytochrome $c$-reductase as well as heme itself occurs in the endoplasmic reticulum during porphyrin photosensitization $(33,34)$. This would lead to the liberation of proteinbound iron that could then participate in the Fenton reactionmediated production of ${ }^{\circ} \mathrm{OH}$. Similarly, ${ }^{\circ} \mathrm{O}_{2}^{-}$can also autodismutate in an aqueous phase into singlet oxygen (51) as shown below:

$$
\begin{aligned}
& \mathrm{O}_{2}^{-}+\mathrm{H}_{2} \mathrm{O} \rightarrow \mathrm{OH}^{-}+\mathrm{HOO}^{\circ} \stackrel{\mathrm{O}_{2}^{-}}{\rightarrow} \\
& \stackrel{\cap}{\cap} \bigcap_{\mathrm{O}-\mathrm{O})^{-}} \rightarrow \mathrm{HOO}^{-}+{ }^{1} \mathrm{O}_{2}
\end{aligned}
$$

The observation that scavengers of ${ }^{1} \mathrm{O}_{2}$ and ${ }^{\circ} \mathrm{OH}$ afforded only partial protection against skin photosensitization while ${ }^{\circ} \mathrm{O}_{2}^{-}$ scavenger was much more protective (12) suggests that singlet oxygen and $\mathrm{OH}$ may be produced secondary to the generation of ${ }^{\circ} \mathrm{O}_{2}^{-}$.

In spite of the modest reactivity of ${ }^{\circ} \mathrm{O}_{2}^{-}$per se, it is capable of inactivating enzymes including RNAases and glyceraldehyde 3-phosphate dehydrogenase (52). However, the ${ }^{\circ} \mathrm{OH},{ }^{1} \mathrm{O}_{2}$, and other oxidants that can be generated from ${ }^{\circ} \mathrm{O}_{2}^{-}$are much more destructive in biological systems (53). The reaction rate of ${ }^{\circ} \mathrm{OH}$ with most organic compounds approaches their diffusion limit, of the order of $10^{-7}-10^{-10} \mathrm{M} / \mathrm{s}$ making them extremely reactive and short-lived $(50,53)$. Because of high reactivity and low diffusion rates these radicals predominantly cause damage very close to and/or at their site of production. As observed by Hilf and his co-workers, the damage in DHEmediated photodestruction of mitochondria was confined to mitochondrial membranes, while absolutely no effects could be observed in the matrix $(42,43)$. These results strengthen the concept that the cutaneous damage in porphyrin photosensitization is mediated mainly through oxygen radicals. Based on 
our results and on previous observations, a possible mechanism of tissue injury and cell death during skin photosensitization and tumor necrosis is proposed in Fig. 7. As shown in the scheme, other strong oxidants like hypochlorous acid, ${ }^{1} \mathrm{O}_{2}$, ' $\mathrm{OH}$, and hydrogen peroxide may be generated by ${ }^{\circ} \mathrm{O}_{2}^{-}$via various enzyme- and nonenzyme-catalyzed pathways. Besides the pivotal role of ${ }^{\circ} \mathrm{O}_{2}^{-}$in tissue photosensitization, these oxidants may also play an important role in exacerbating tissue injury.

In conclusion our data suggest that ${ }^{\circ} \mathrm{O}_{2}^{-}$is involved in DHE-mediated cutaneous photosensitization and that it can be generated through the $\mathrm{Ca}$-dependent activation of xanthine oxidase. The generation of ${ }^{\circ} \mathrm{OH},{ }^{1} \mathrm{O}_{2}$, and other strong oxidants may occur secondary to $\mathrm{O}_{2}^{-}$formation and may play additive roles in mediating tissue injury. It is also tempting to suggest that similar mechanisms may be operative for DHE-mediated tumor necrosis. These results may have direct implications for the development of newer drugs for PDT and may suggest new directions in the search for drugs that can suppress porphyrin photosensitization.

\section{Acknowledgments}

We acknowledge the help of Dr. M. T. Zaim, University Hospitals of Cleveland, for histopathological evaluations, and of Mr. Jerry M. Reed of the Chemistry Department, Case Western Reserve University, for recording ESR spectra. We thank Professor N. L. Oleinick and Dr. J. J. Ellner for the critical review of the manuscript. Thanks are also due to Ms. Sandra Evans for preparing the manuscript.

This work was supported by U. S. Public Health Service grants AM-34368, CA-38028, AM-32593, ES-1900, and P30-CA43703, by Environmental Protection Agency grant RR-813324, and by research funds from the Veterans Administration. Dr. Athar is a recipient of the Hoechst-Russell Research Fellowship Award by the Dermatology Foundation. Dr. Elmets is the recipient of a National Institutes of Health Research Career Development Award (AR-01765).

\section{References}

1. Bickers, D. R. 1983. Photosensitization by porphyrins. In Biochemistry and Physiology of Skin, vol. II. L. A. Goldsmith, editor. Oxford University Press, New York. 755-768.

2. Dougherty, T. J., K. R. Weishaupt, and D. G. Boyle. 1985. Photodynamic sensitizers. In Principles and Practice of Oncology. V. DeVita, Jr., S. Hellman, and S. Rosenberg, editors. J. B. Lippincott Co., Philadelphia. 2272-2279.

3. Kessel, D. 1986. Photosensitization with derivatives of haematoporphyrin. Int. J. Radiat. Oncol. Biol. Phys. 49:901-907.

4. Kessel, D. 1986. Proposed structure of the tumor-localizing fraction of HPD (hematoporphyrin derivative). Photochem. Photobiol. 44:193-196.

5. Gomer, C. J., and N. J. Razum. 1984. Acute skin response in albino mice following porphyrin photosensitization under oxic and anoxic conditions. Photochem. Photobiol. 40:435-439.

6. Henderson, B. W., and V. H. Fingar. 1987. Relationship of tumor hypoxia and response to photodynamic treatment in the RIF experimental mouse tumor. Cancer Res. 47:3110-3114.

7. Thomas, J. P., R. D. Hall, and A. W. Girotti. 1987. Singlet oxygen intermediacy in the photodynamic action of membrane-bound hematoporphyrin derivative. Cancer Lett. 35:295-302.

8. Buethner, G. R., and L. W. Oberley. 1980. Apparent production of superoxide and hydroxyl radicals by hematoporphyrin and light as seen by spin trapping. FEBS (Fed. Eur. Biochem. Soc.) Lett. 121:161164.

9. Krall, J., A. C. Bagley, G. T. Mullenbach, R. A. Hellewell, and R. E. Lynch. 1988. Superoxide mediates the toxicity of paraquat for cultured mammalian cells. J. Biol. Chem. 263:1910-1914.
10. Zweier J. L. 1988. Measurement of superoxide-derived free radicals in the reperfused heart. J. Biol. Chem. 263:1353-1357.

11. Burnutte, J. T., J. A. Badney, J. M. Robinson, M. J. Karnovsky, and M. L. Karnovsky. 1984. Studies on the mechanism of superoxide release from human neutrophiles stimulated with arachidonate. $J$. Biol. Chem. 259:11851-11857.

12. Athar, M., H. Mukhtar, C. A. Elmets, M. T. Zaim, J. R. Lloyd, and D. R. Bickers. 1988. In situ evidence for the involvement of superoxide anions in cutaneous porphyrin photosensitization. Biochem. Biophys. Res. Commun. 151:1054-1059.

13. Dougherty, T. J. 1987. Photosensitizers: therapy and detection of malignant tumors. Photochem. Photobiol. 45:879-889.

14. Myers, C. L., S. J. Weiss, M. M. Kirsh, and M. Shlafer. 1985. Involvement of hydrogen peroxide and hydroxyl radical in the 'Oxygen Paradox': reduction of creatine kinase release by catalase, allopurinol or deferoxamine, but not by superoxide dismutase. J. Mol. Cell. Cardiol. 17:675-684.

15. Sorenson, J. R. J. 1976. Copper chelates as possible active forms of the antiarthritic agents. J. Med. Chem. 19:135-147.

16. Goldstein, B. D., M. G. Rozen, J. C. Quintavalla, and M. A. Amoruso. 1979. Decrease in mouse lung and liver glutathione peroxidase activity and potentiation of the lethal effects of ozone and paraquat by the superoxide dismutase inhibitor diethyl dithocarbamate. Biochem. Pharmacol. 28:27-30.

17. Elmets, C. A., R. L. Lewen, W. A. Khan, H. Mukhtar, and D. R. Bickers. 1987. Photofrin-II photodynamic therapy: pharmacokinetics and efficacy in the treatment of chemically induced skin tumors in mice. Photochem. Photobiol. 45:1035.

18. Elmets, C. A., P. R. Bergstresser, R. E. Tigelaar, P. J. Wood, and J. W. Streilein. 1983. Analysis of the mechanism of unresponsiveness produced by haptens painted on skin exposed to low dose ultraviolet radiation. J. Exp. Med. 158:781-794.

19. Hawkins, C. W., D. R. Bickers, H. Mukhtar, and C. A. Elmets. 1986. Cutaneous porphyrin photosensitization: murine ear swelling as a marker of the acute response. J. Invest. Dermatol. 86:638-642.

20. Athar, M., H. Mukhtar, and D. R. Bickers. 1988. Differential role of reactive oxygen intermediates in photofrin-I and photofrin-II mediated photoenhancement of lipid peroxidation in epidermal microsomal membranes. J. Invest. Dermatol. 90:652-657.

21. Heinz, F., and S. Reckel. 1983. Xanthine oxidase. In Methods of Enzymatic Analysis, vol. II. H. U. Bergmeyer, editor. Verlag Chemie GmbH, Weinheim, FRG. 210-215.

22. McBurney, A., and T. Gibson. 1980. Reverse phase partition HPLC for determination of plasma purines and pyrimidines in subjects with gout and renal failure. Clin. Chim. Acta. 102:19-28.

23. Fridovich, I. 1970. Quantitative aspects of the production of superoxide anion radical by milk xanthine oxidase. J. Biol. Chem. 245:4053-4057.

24. Chambers, D. E., D. A. Parks, G. Patterson, R. Roy, J. M. McCord, M. Yoshida, L. F. Pammley, and J. M. Downey. 1985. Xanthine oxidase as a source of free radical damage in myocarial ischemia. J. Mol. Cell. Cardiol. 17:145-152.

25. Spector, T., and D. G. John. 1970. Stoichiometric inhibition of reduced xanthine oxidase by hydroxypyrazolo[3,4-d]pyrimidines. $J$. Biol. Chem. 245:5079-5085.

26. Minotti, G., and S. D. Aust. 1987. The requirement for iron (III) in the initiation of lipid peroxidation by iron (II) and hydrogen peroxide. J. Biol. Chem. 262:1098-1 104.

27. Hilton, B. D., R. Misra, and J. L. Zweier. 1986. Magnetic resonance studies of fredericamycin $A$ : evidence for $\mathrm{O}_{2}^{-}$dependent free radical formation. Biochemistry. 25:5533-5539.

28. Zweier, J. L., L. Gianni, J. Muindi, and C. E. Myers. 1986. Differences of $\mathrm{O}_{2}$ reduction by the iron complexes of adriamycin and daunomycin: the importance of side chain hydroxyl group. Biochim. Biophys. Acta. 884:326-336.

29. Zwier, J. L., B. K. Rayburn, J. T. Flaherty, and M. L. Weisfeldt. 1987. Recombinant superoxide dismutase reduces oxygen free radical 
concentrations in reperfused myocardium. J. Clin. Invest. 80:17281734.

30. Al-Khalidi, U. A. S., and T. H. Chaglassian. 1965. The species distribution of xanthine oxidase. Biochem. J. 97:318-320.

31. Korthius, R. J., and D. N. Granger. 1986. Ischemia-reperfusion injury: role of oxygen-derived free radicals. In Physiology of Oxygen Radicals. A. E. Taylor, S. Matalon, and P. A. Ward, editors. American Physiological Society, Bethesda, MD. 217-250.

32. Corte, E. D., and F. Stirpe. 1972. The regulation of rat liver xanthine oxidase. Biochem. J. 126:739-745.

33. Dixit, R., H. Mukhtar, and D. R. Bickers. 1983. Destruction of microsomal cytochrome $\mathrm{P}-450$ by reactive oxygen species generated during photosensitization of hematoporphyrin derivative. Photochem. Photobiol. 37:173-176.

34. Das, M., H. Mukhtar, E. R. Greenspan, and D. R. Bickers. 1985. Photoenhancement of lipid peroxidation associated with the generation of reactive oxygen species in hepatic microsomes of hematoporphyrin derivative-treated rats. Cancer Res. 45:6328-6330.

35. Gibson, S. L., and R. Hilf. 1983. Photosensitization of mitochondrial cytochrome $c$ oxidase by hematoporphyrin derivative and related porphyrins in vitro and in vivo. Cancer Res. 43:4191-4197.

36. Kessel, D. 1984. Hematoporphyrin and HPD: photophysic, photochemistry and phototherapy. Photochem. Photobiol. 39:851859.

37. Torinuki, W., T. Miura, and M. Seiji. 1980. Lysosome destruction and lipid peroxide formation due to active oxygen generated from hematoporphyrin and U.V. irradiation. Br. J. Dermatol. 102:17-27.

38. Harber, L. C., and D. R. Bickers. 1981. Photosensitivity Diseases: Principles of Diagnosis and Treatment. W. B. Saunders Co., Philadelphia. $372 \mathrm{pp}$.

39. Girotti, A. W. 1983. Mechanisms of photosensitization. Photochem. Photobiol. 38:745-751.

40. Kessel, D. 1986. Sites of photosensitization by derivatives of hematoporphyrin. Photochem. Photobiol. 44:489-493.

41. Salet, C., G. Moreno, and F. Vinzens. 1983. Effect of photodynamic action on energy coupling of $\mathrm{Ca}^{2+}$ uptake in liver mitochondria. Biochem. Biophys. Res. Commun. 115:76-81.

42. Hilf, R., R. S. Murant, U. Narayanan, and S. L. Gibson. 1986.
Relationship of mitochondrial function and cellular adenosine triphosphate levels to hematoporphyrin derivative-induced photosensitization in R3230AC mammary tumors. Cancer Res. 46:211-217.

43. Hilf, R., S. L. Gibson, D. P. Penney, T. L. Ceckler, and R. G. Bryant. 1987. Early biochemical responses to photodynamic therapy monitored by NMR spectroscopy. Photochem. Photobiol. 46:809-818.

44. Reiners, J. J., Jr., B. C. Pence, C. S. Barcus, and A. R. Cantu. 1978. 12-O-Tetradecanoylphorbol-13-acetate-dependent induction of xanthine dehydrogenase and conversion of xanthine oxidase in murine epidermis. Cancer Res. 47:1775-1779.

45. Yavelow, J., T. H. Finlay, A. R. Kennedy, and W. Troll. 1983. Bowman-Birk soybean protease inhibitor as an anticarcinogen. Cancer Res. 43:2454-2459.

46. Finklestein, E., G. M. Rosne, and E. J. Rauchman. 1980. Spin trapping of superoxide and hydroxyl radical: practical aspects. Arch. Biochem. Biophys. 200:1-16.

47. Fridovich, I. 1978. The biology of oxygen radicals: the superoxide radical is an agent of oxygen toxicity; superoxide dismutases provide an important defense. Science (Wash. DC). 201:875-879.

48. Klebanoff, S. J. 1980. Myeloperoxidase mediates cytotoxic system. In The Reticuloendothelial System: A Comprehensive Treatise, vol. 2. A. J. Sbarra and R. Strauss, editors. Plenum Publishing Corp., New York. 279-308.

49. Wasil, M., B. Halliwell, M. Grootveld, C. P. Moorhouse D. C. S. Hutchison, and H. Baum. 1987. The specificity of thiourea, dimethyl thiourea and dimethyl sulfoxide as scavengers of hydroxyl radicals. Biochem. J. 243:867-870.

50. Youngman, R. J. 1983. Oxygen activation: is the hydroxyl radical always biologically relevant? Trends Biochem. Sci. 9:280-283.

51. Corey, E. J., M. M. Mehrotra, and A. U. Khan. 1987. Water induced dismutation of superoxide anion generates singlet molecular oxygen. Biochem. Biophys. Res. Commun. 145:842-846.

52. Lavelle, F., A. M. Michelson, and L. Dimitrijevic. 1973. Biological protection by superoxide dismutase. Biochem. Biophys. Res. Commun. 55:305-357.

53. Kalyanaraman, B., and P. G. Suhnle. 1985. Generation of free radical intermediates from foreign compounds by neutrophil-derived oxidants. J. Clin. Invest. 75:1618-1622. 